\title{
Photovoltaic Measurement Using Microprocessor Logger and Current Sensor
}

\author{
Rhezal Agung Ananto ${ }^{1}$, and Rudy Setiabudy ${ }^{1, *}$ \\ ${ }^{1}$ Electrical Engineering Department, Universitas Indonesia, Kampus Baru UI Depok 16424, \\ Indonesia
}

\begin{abstract}
Nowdays, energy demand increase every years. Some obstacles stand in the way of energy supply. Some obstacles are energy limitation, climate change and environmental regulation. The change of conventional energy to renewable energy is the future solution. The development of renewable energy is the main priority, based on Indonesian government regulations. The potential of solar energy in Indonesia is very large because it is located in the equator. The research tries to measure solar energy in Indonesia region, it use atmega328p microprocessor logger and INA219 current sensor module. The measurement result is used to determine the photovoltaic stand-alone system performance. Measurement variables are sun irradiance, voltage, current, power, energy and temperature. The research method is measurement comparison between photovoltaic system with maximum power point tracking (MPPT) and without MPPT. Sun irradiation measurement with solar power meter is compared with sun irradiation data from NASA. Performance Ratio of the photovoltaic system with MPPT is better than the photovoltaic system without MPPT, the best photovoltaic system with MPPT Performance Ratio (PR) result is 0.93 .
\end{abstract}

\section{Introduction}

Today, energy demand is increasing every year. Some obstacles are energy limitation, climate change and environmental regulation. Currently, most of the primary energy sources are oil and gas. The change of conventional energy to renewable energy is the future solution. One of the biggest potential energy in the future is solar energy. Solar energy is one of renewable energy. The development of renewable energy is the main priority, based on Indonesian government regulations. Indonesia is also located on the equator, which has solar energy every years. Base on the above problems, the research is expected to be useful in the future to develop solar energy in Indonesia.

An effective Photovoltaic power system is needed to convert solar energy into electrical energy. This system is needed because the energy produced by Photovoltaic is not constant, based on weather condition. Some of the Photovoltaic systems are Photovoltaic stand-alone system and microgrid system [1].

\footnotetext{
* Corresponding author: rudy@eng.ui.ac.id
} 
Performance measurements of Photovoltaic systems are required to obtain effective solar power generation systems. The measurement of solar power performance based on IEC 61724 is the photovoltaic Performance ratio (PR). Example of photovoltaic performance ratio is short-term performance ratio measurements performed in subtropical climates in India. In India, PR (performance ratio) results are 0.74; 0.78; and 0.76 [2].

This Measurement is located in the tropical climates of Indonesia. Malaysia is the closest country, it has the same tropical climates characteristic. The results of performance Ratio (PR) measurements in Malaysia during 4 days of measurements are 0.5940;0.4481; and 0.280 [3]. The Performance ratio results from other research in the same area are 0.75 ; $0.77 ; 0.78 ; 0.82 ; 0.84 ; 0.85$; and 0.92 . The research locations are located in several city in Indonesia. The locations are Surabaya, Kupang, and Tangerang Selatan[4-6]. In this paper, the photovoltaic measurement is located in kabupaten Malang, East Java Province, Indonesia (tropical climates area).

\section{Photovoltaic Stand-alone System and Performance Ratio}

Photovoltaic systems require several essential elements to support a Photovoltaic standalone system running effectively. One of the necessary essential elements is the battery. Batteries are useful for saving energy during the day, when Photovoltaic produces energy. Charge controller is useful to protect against battery overcharging (protect from burning) and to set power on Maximum Power Point(as MPPT). 12V DC load does not require a $\mathrm{DC} / \mathrm{DC}$ converter and $\mathrm{AC}$ load required $\mathrm{DC} / \mathrm{AC}$ inverter.

Performance ratio is used to determine the performance of Photovoltaic system. Based on the IEC 61724 standard, performance ratio is the actual energy ratio of Photovoltaic system with reference energy (energy measurement in the region) [7]. Calculating Performance Ratio (PR) takes several parameters, according to IEC 61724 standard, we can see the following parameters; $E_{\text {out }}$ (Photovoltaic Output Energy $(\mathrm{kWh})$ ), $P_{0}$ (Photovoltaic Power rating $(\mathrm{kWp})), H_{i}\left(\right.$ In-Plane irradiation $\left.\left(\mathrm{kWh} / \mathrm{m}^{2}\right)\right)$, and $G_{i, \text { ref }}$ ( in-plane irradiance peak reference $1000\left(\mathrm{~W} / \mathrm{m}^{2}\right)$ ). Formula of Performance ratio calculation (PR) is the formula below,

$$
P R=\frac{E_{\text {out }} / P_{0}}{H_{i} / G_{i, r q f}}
$$

This formula is commonly called the traditional performance ratio, because this formula does not consider the module temperature.

\section{Methodology}

This study is comparing performance ratio of two different photovoltaic system. Two different photovoltaic system are installed in the same location. First system is photovoltaic system with MPPT and second system is photovoltaic system without MPPT (photovoltaic direct to load). Power measurement using atmega328p microprocessor logger and INA219 curent sensor. Sun irradiance power measurement using solar power meter. First photovoltaic system has $P_{0}=10 \mathrm{Wp}$ (Polycrystalline PV Panel), $V_{m p}=17.2 \mathrm{~V}, I_{m p}=0.58 \mathrm{~A}$, $\mathrm{MPPT}=10 \mathrm{~A}$; and Battery $=12 \mathrm{~V} / 60 \mathrm{Ah}$. Second photovoltaic system has $P_{0}=10 \mathrm{Wp}$ (Polycrystalline PV Panel), $V_{m p}=17.2 \mathrm{~V}, I_{m p}=0.58 \mathrm{~A}$, and load $30 \mathrm{ohm}$.

Design of logger atmega328p and INA219 current sensor has good error test result. The logger error results are $0.29 \%-1.16 \%$ (voltage) and $0.19 \%-0.57 \%$ (current).

First photovoltaic system, current sensor INA219 logger is installed between photovoltaic module and maximum power point tracking (MPPT). Second photovoltaic system, current sensor is installed between photovoltaic module and load. Current sensor 
Logger can measure voltage, current and time. The measurement parameter is recorded in micro-sd card using micro-sd module every 0.5 second. The sun irradiance mesurement is recorded every 2 second using solar power meter in micro-sd card. Solar power meter is installed near photovoltaic location. Figure 1 below is the installation of current sensor and research configuration block diagram.

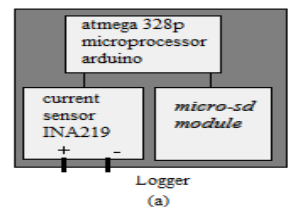

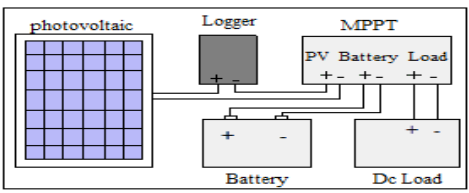

(b)

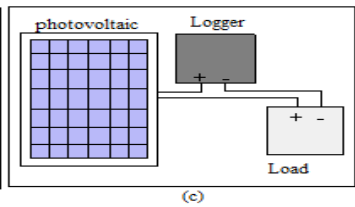

Fig. 1. Block Diagram (a) Logger current sensor (b) PV with MPPT (c) PV without MPPT.

Energy can calculate with equation (2) below,

$$
E_{\text {out }}=\frac{p}{3600 \times\left(\frac{1000}{\Delta t}\right)}=\frac{V \times I}{3600 \times\left(\frac{1000}{\Delta t}\right)}
$$

With $V=$ Voltage (volt), $I=$ Current (ampere), $E_{\text {out }}=\operatorname{Energy}(\mathrm{Wh}), P=$ Power (watt) and $\Delta t=$ delta sampling time (milliSeconds).

\section{Result and Discussion}

Photovoltaic performance ratio measurement is located in kabupaten malang, east Java, Indonesia. The comparison photovoltaic system PR and sun irradiation measurement results can be seen in Table 1 below,

Table 1. Sun Irradiance Measurement Using Solar Power Meter and Performance Ratio.

\begin{tabular}{|r|r|r|r|r|r|r|r|}
\hline \multirow{2}{*}{ Date } & \multirow{2}{*}{$\begin{array}{c}\boldsymbol{H}_{\boldsymbol{i}} \\
\mathbf{2}\end{array}$} & \multicolumn{2}{|c|}{ Without MPPT } & \multicolumn{2}{|c|}{ With MPPT } & \multirow{2}{*}{$\mathbf{T}\left({ }^{\mathbf{0}} \mathbf{C}\right)$} \\
\cline { 4 - 7 } 28 & April & 7054.54 & 55513.13 & 0.79 & 32384.03 & 0.46 & 25.64 \\
\hline 29 & April & 7255.42 & 54970.67 & 0.76 & 32384.03 & 0.45 & 25.33 \\
\hline 4 & May & 7138.51 & 58007.39 & 0.81 & 37758.06 & 0.53 & 24.42 \\
\hline 5 & May & 5976.52 & 46036.15 & 0.77 & 53859.38 & 0.90 & 24.74 \\
\hline 6 & May & 6592.79 & 52417.99 & 0.80 & 58723.57 & 0.89 & 26.32 \\
\hline 7 & May & 6881.85 & 55351.16 & 0.80 & 63495.24 & 0.92 & 25.79 \\
\hline 8 & May & 6951.75 & 56031.09 & 0.81 & 52645.93 & 0.76 & 25.75 \\
\hline 9 & May & 6938.77 & 55917.11 & 0.81 & 32716.02 & 0.47 & 25.20 \\
\hline 10 & May & 6659.63 & 53716.27 & 0.81 & 60810.84 & 0.91 & 26.32 \\
\hline 11 & May & 6736.32 & 54648.34 & 0.81 & 61970.78 & 0.92 & 25.01 \\
\hline 12 & May & 6643.46 & 55334.03 & 0.83 & 61985.51 & 0.93 & 24.76 \\
\hline
\end{tabular}

$H_{i}$, and $E_{\text {out }}$ data in Table 1 are obtained with solar power meter measurement output data and microprosessor logger measurement output data. Performance Ratio (PR) photovoltaic system in Table 1 can calculate with equation (1). The calculation below is Example of PR calculation 12 may 2018 (with MPPT). PR $=[61985.51$ $\mathrm{mWh} / 10000 \mathrm{mWp}] /\left[\left(6643.46 \mathrm{Wh} / \mathrm{m}^{2} /\right.\right.$ day $\left.) /\left(1000 \mathrm{~W} / \mathrm{m}^{2}\right)\right]=0.93$.

The lowest Performance ratio (PR) result of the two systems is 0.45 . The highest PR result of the two system is 0.93 . The performance ratio result is affected by the solar irradiance. The solar iradiance is directly proportional to the performance ratio of the system. The performance ratio of the system with MPPT is affected by the battery condition when charging process occurs. When the battery condition is full performance ratio will decrease by less than 0,5 . The power measurement 28 april 2018(full battery conditon) and 12 may 2018 (battery condition is not full) results can be seen in Figure 2 
below. The Figure 2 below can be used to understand the battery condition effect on Performance ratio result.

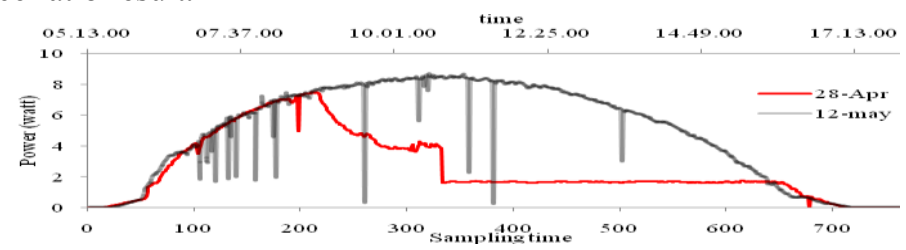

Fig. 2. Power Chart with MPPT 28 April 2018 and 12 may 2018 (comparison of battery condition).

Figure 2 above is photovoltaic system with MPPT power chart with different battery condition. The chart start at 05.13 o'clock in the morning and finish at 18.10 o'clock in the evening. The highest power on 28 april 2018 (battery condition is full) is 7.473 watts at 08.45 o'clock, and the highest power on 12 may 2018 (battery condition is not full) is 8.703 watts at 10.34 o'clock.

The performance ratio decreases due to the battery condition. The current limiting is active, when battery condition is full. This system works because MPPT has current limiting system, so the battery is not overcharged (burned). Performance ratio will be high when battery condition is not full. The condition can be seen in Figure 2 (12 may). The chart indicates that the current limiting system is not active.

The photovoltaic system without MPPT produces voltage based on the characteristics of the photovoltaic loadline I/V characteristic curve. The photovoltaic can not set voltage to the maximum power point (MPP).

The photovoltaic system with MPPT produces voltage base on maximum power point (MPP) voltage. DC/DC converter is setted by maximum power point tracking (MPPT) to set maximum power point (MPP) voltage. The comparison voltage of two photovoltaic system and sun irradiance can be seen in Figure 3 below.
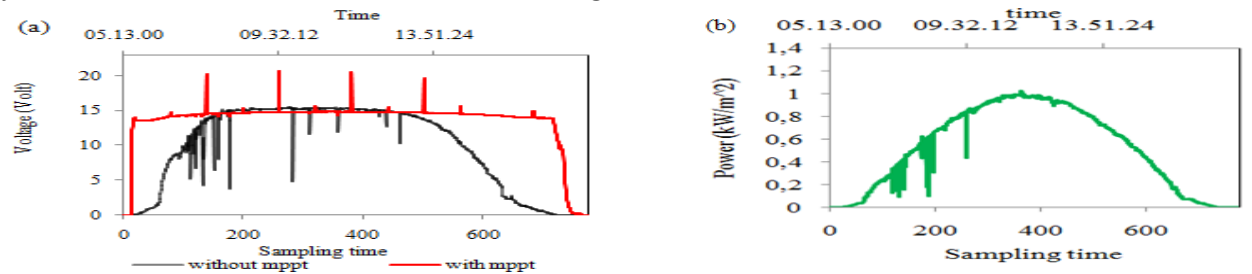

Fig. 3. Chart 12 May 2018 (a) Comparison voltage with MPPT and without MPPT (b) sun Irradiance.

Figure 3. (a) above is voltage chart of photovoltaic system. The chart start at 05.13 o'clock and finish at 18.10 o'clock in the evening. Photovoltaic system with MPPT, the voltage start at 05.27 o'clock in the morning (11.58 volts) and finish at 17.57 o'clock in the eveing ( 0.2 volts). Photovoltaic system without MPPT, the voltage chart start at 05.27 o'clock in the morning $(0.01$ volt $)$ and finish at 17.21 o'clock in the evening ( 0.02 volts).

Figure 3. (b) above is sun irradiance power chart. The chart start at 05.13 o'clock and finish at 18.10 o'clock in the evening. The Power start at 05.27 o'clock in the morning $(0.8$ watts $\left./ \mathrm{m}^{2}\right)$ finish at 17.45 o'clock in the evening $\left(0.1 \mathrm{watt} / \mathrm{m}^{2}\right)$. The highest Sun irradiance power is 1021 watts $/ \mathrm{m}^{2}$ at 11.15 o'clock.

The two figure above show that the voltage of the photovoltaic system with MPPT does not follow the solar radiation power, which means it does not follow the sun irradiance and $\mathrm{I} / \mathrm{V}$ characteristics curve.

The average performance ratio of the photovoltaic system without MPPT is 0.79 and the average performance ratio of the photovoltaic system with MPPT is 0.74 (measurement solar radiation using solar power meter). The PR result of photovoltaic system without MPPT is higher than photovoltaic system with MPPT, but photovoltaic system can not be 
used to charge the battery 12 volts, because some voltages are below 12 volts. The PR result of the photovoltaic system with MPPT is better than the photovoltaic system without MPPT, when the battery is not full.

Performance ratio calculation based on average solar radiation data from NASA (6.899167 $\mathrm{kWh} / \mathrm{m}^{2} /$ day) [8] can be seen in Table 2 below;

Table 2. NASA Irradiance Data and Performance Ratio.

\begin{tabular}{|c|c|c|c|c|c|c|}
\hline \multirow{2}{*}{\multicolumn{2}{|c|}{ Date }} & \multirow{2}{*}{$\begin{array}{c}H_{i} \\
\left(\mathbf{W h} / \mathrm{m}^{2} / \text { day }\right)\end{array}$} & \multicolumn{2}{|c|}{ Without MPPT } & \multicolumn{2}{|c|}{ With MPPT } \\
\hline & & & $E_{\theta}(\mathrm{mWh})$ & PR & $E_{0}(\mathrm{mWh})$ & PR \\
\hline 28 & April & 6899.16 & 55513.13 & 0.80 & 32384.03 & 0.47 \\
\hline 29 & April & 6899.16 & 54970.67 & 0.80 & 32384.03 & 0.47 \\
\hline 4 & May & 6899.16 & 58007.39 & 0.84 & 37758.06 & 0.55 \\
\hline 5 & May & 6899.16 & 46036.15 & 0.67 & 53859.38 & 0.78 \\
\hline 6 & May & 6899.16 & 52417.99 & 0.76 & 58723.57 & 0.85 \\
\hline 7 & May & 6899.16 & 55351.16 & 0.80 & 63495.24 & 0.92 \\
\hline 8 & May & 6899.16 & 56031.09 & 0.81 & 52645.93 & 0.76 \\
\hline 9 & May & 6899.16 & 55917.11 & 0.81 & 32716.02 & 0.47 \\
\hline 10 & May & 6899.16 & 53716.27 & 0.78 & 60810.84 & 0.88 \\
\hline 11 & May & 6899.16 & 54648.34 & 0.79 & 61970.78 & 0.90 \\
\hline 12 & May & 6899.16 & 55334.03 & 0.80 & 61985.51 & 0.90 \\
\hline
\end{tabular}

Table 2 above is the results of performance ratio using NASA data. Photovoltaic system without MPPT, the lowest performance ratio result is 0.67 and the highest performance ratio result is 0.84 . Photovoltaic system with MPPT, the lowest performance ratio result is 0.47 and the highest performance ratio result is 0.90 . The measurement start on 28 april 2018 and finish on 12 may 2018.

The photovoltaic system without MPPT, The average result difference between sun irradiance measurement and NASA sun irradiance is 0.028561 . The photovoltaic system with MPPT, the average result difference between sun irradiance measurement and NASA sun irradiance is 0.028236 . The result difference occur because the calculation of PR is only influenced by Photovoltaic power.

Comparison different photovoltaic system performance ratio with other reasearch in same area (at least on the same grid) can be seen in tabel.3. below;

Table 3. the research PR results and another research PR results

\begin{tabular}{|l|r|l|r|}
\hline Measurement area & Performance Ratio & Measurement area & Performance Ratio \\
\hline Malang & $0.74 ; 0.79$ & Kupang [5] & 0.82 \\
\hline Malang (NASA data) & $0.72 ; 0.79$ & Surabaya [6] & $0.75 ; 0.77 ; 0.84$ \\
\hline Tangerang Selatan[4] & $0.78 ; 0.85 ; 0.92$ & Malaysia [3] & $0.280 .45 ; 0.59$ \\
\hline
\end{tabular}

The lowest Performance Ratio (PR) result from other research in same area is 0.28 . The highest PR result from other reasearch in same area is 0.92. Performance Ratio (PR) result in tangerang selatan is the highest result (0.92). Malaysia performance ratio (PR) is the lowest result (0.28). The Photovoltaic system with MPPT, the result difference between malang area and another area can be calculated with Table 3 data.

The lowest Performance Ratio (PR) difference results is 0.01 and the highest PR difference result is 0.51 . PR diference results between malang (PV system with MPPT) and Tangerang selatan are $0.01 ; 0.06$; and 0.13 . PR diference result between malang (PV system with MPPT) and Kupang is 0.03 . PR diference results between malang (PV system with MPPT) and Surabaya are 0.02; 0.04; and 0.05. PR diference results between malang (PV system with MPPT) and Malaysia are $0.2 ; 0.34$; and 0.51 .

The PR result betwen malang and surabaya has almost the same value. This result indicated that the measurement is accurate, because surabaya is the closest area from 
malang. The PR result difference in indonesia area is not significant. the PR results difference are $0.01 ; 0.02 ; 0.03 ; 0.04 ; 0.05 ; 0.06$ and 0.13 . The PR result difference is not significant because the area is located in same tropical climate. The PR result difference is affected by weather condition. For example, average sun irradiance between malang and kupang is different.

Average sun irradince in Malang $6899.16 \mathrm{kWh} / \mathrm{m}^{2} /$ day and average sun iradiance in Kupang $6362.50 \mathrm{Wh} / \mathrm{m}^{2} /$ day [8].

\section{Conclusions}

Photovoltaic system performance ratio result is affected by sun irradiance and the DC/DC converter system of MPPT. DC/DC converter set voltage to the MPP voltage. The photovoltaic power will be optimum and photovoltaic performance ratio will be optimum. The average PR of the photovoltaic system without MPPT is 0.79 and the average PR photovoltaic system with MPPT is 0.74 .

Performance ratio of Photovoltaic stand-alone systems is affected by battery condition (battery condition is full or battery conditions is not full). Performance Ratio (PR) will decrease, when the battery condition is full. The lowest PR result system with MPPT is 0.46 , when the battery condition is full.

Performance Ratio of photovoltaic system with MPPT is better than the photovoltaic system without MPPT, when the battery condition is not full. The best PR result of the system with MPPT is 0.93 , when the battery condition is not full.

The design of logger microprocessor and current sensor has good error test result. The logger error results are $0.29 \%-1.16 \%$ (voltage) and $0.19 \%-0.57 \%$ (current).

The PR result difference in Indonesia area is not significant. The PR results difference are $0.01 ; 0.02 ; 0.03 ; 0.04 ; 0.05 ; 0.06$ and 0.13 . The PR result difference is not significant because the area is located in same tropical climate. The PR result difference is affected by weather condition.

\section{Acknowledgement}

This research financed by DRPM UI, PITTA grand scheme No: 2524/UN2.R3.1/HKP.05.00/2018.

\section{References}

1. B.S. Hartono, Y. Budiyanto and R. Setiabudy, Quality in Research, 127-132 (2013)

2. T. Georgitsioti, G. Pillai, N. Pearsall, G. Putrus, I. Forbes and R. Anand, IET Renewable Power Generation, 9(5), 438-445 (2015)

3. Ghazali. A M., and Rahman, AMA, Energy and Environment Research, 2(1), 235-243 (2012)

4. O.A. Rosyid, Smart Cities, Automation \& Intelligent Computing System, 81-86 (2017)

5. I.N.S. Kumara, M. Ashari, A.S. Sampeallo, and A.A.G.A. Pawitra, International Journal of Engineering and Technology innovation, 7(2), 117-129 (2018)

6. Elieser Tarigan, Djuwari, and Lasman Purba, Energy Procedia, 47, 85-93 (2014)

7. IEC 61724, Photovoltai system performance monitoring. Guidelines for measurement, data exchange and analysis, (1999)

8. NASA Surface Meteorology and Solar Energy, https://eosweb.larc.nasa.gov/cgibin/sse/grid.cgi?email=skip@larc.nasa.gov (Accesed 1 May 2018) 